\title{
The association of gegenhalten in the upper limbs with dyspraxia
}

\author{
P TYRRELL, M ROSSOR \\ From the Department of Neurology, St Mary's Hospital, and The National Hospital for Nervous Diseases, \\ London, UK
}

SUMMARY Ten patients with gegenhalten of the upper limb of mixed aetiology were studied, in nine of whom an association with dyspraxia was found. In four of the patients, the rigidity became more pronounced after the instruction to relax, and only one patient showed improvement after this instruction. In these patients, the resistance to movement, evident as gegenhalten, may be a direct consequence of the dyspraxia.

Gegenhalten $^{1}$ and paratonic rigidity ${ }^{2}$ are terms used to describe an increase in muscle tone which occurs in response to passive movement, and which is proportional in degree to the stimulus applied. It is seen most commonly in the legs, but in some instances we have observed gegenhalten in the upper rather than the lower limbs in patients with dyspraxia. This observation, and the fact that gegenhalten is often exacerbated by the verbal command to relax, led to the investigation of the association between gegenhalten and dyspraxia.

\section{Methods}

Ten successive patients with gegenhalten of the upper limbs were assessed for dyspraxia. Patients who were unable to understand simple commands (that is, who were unable to respond appropriately to a command such as "clench your left fist") were excluded from the study, as were patients on psychotropic medication. Gegenhalten was defined as a rigidity of the limb detected on passive movement, occurring in the absence of cogwheeling or a spastic catch, that was not exacerbated by movement in the contralateral fist. Movements tested were wrist flexion and extension, forearm pronation and supination, elbow flexion and extension, flexion and extension of the knee, and rotation at the hip. Each movement was performed five times by the examiner, initially with no instruction to the patient. Elbow and knee flexion/extension were then repeated in turn, initially while the patient was opening and closing the contralateral fist, again while counting backwards from 10 , and then after the instruction to relax. The limb placement manoeuvre was also assessed, because this has been used by others as a test for paratonia. $^{34}$ The examiner held up the subject's arm and told him to relax, letting the examiner take the weight; the examiner then dropped his hands. The subject's arm should fall at the same time, and any delay in dropping of the arm was considered abnormal. ${ }^{3}$ Any patient with limb weakness, brisk reflexes, extensor plantar responses, or spastic catch or cogwheeling was excluded from the study. Dyspraxia was assessed on the basis of inability to copy gestures and commands, ${ }^{5}$ despite apparently normal coordination, sensation and power, in the upper and lower limbs, and orofacial muscles.

The following movements were assessed.

(1) Upper limb:

Copying gestures: (with each hand in turn).

1 making a fist

2 point with finger

3 pointing upwards with thumb

4 index and little finger pointing to ceiling

5 thumb and forefingers interlocked

\section{(2) Lower limb:}

1 bicycling movements

2 describing a circle in the air with great toe (each side in turn).
(3) Orofacial:
1 sticking out tongue
2 blowing a kiss
3 coughing.

\section{(4) Complex movements:}

1 lighting a match

2 cutting paper with scissors.

Ten consecutive patients with gegenhalten of the upper limb were studied. Four of these had dementia of Alzheimer type (DAT), of whom two (table) had grasp reflexes. One patient had dementia thought to be of mixed Alzheimer and vascular type, because of mild hypertension, and mixed pos- 
Table Results

\begin{tabular}{|c|c|c|c|c|c|c|c|c|c|c|}
\hline \multirow[b]{2}{*}{ Patient } & \multirow[b]{2}{*}{ Age } & \multirow[b]{2}{*}{ Sex } & \multirow[b]{2}{*}{ Diagnosis } & \multicolumn{3}{|l|}{ Apraxia } & \multicolumn{2}{|l|}{ Gegenhalten } & \multirow{2}{*}{$\begin{array}{l}\text { Limb placement } \\
\text { sign }\end{array}$} & \multirow{2}{*}{$\begin{array}{l}\text { Instruction to } \\
\text { relax }\end{array}$} \\
\hline & & & & upper limb & lower $\operatorname{limb}$ & orofacial & upper $\operatorname{limb}$ & lower limb & & \\
\hline $\begin{array}{r}1 \\
2 \\
3 \\
4 \\
5 \\
6 \\
7 \\
8 \\
9 \\
10\end{array}$ & $\begin{array}{l}68 \\
72 \\
74 \\
82 \\
68 \\
53 \\
69 \\
64 \\
64 \\
69\end{array}$ & $\begin{array}{l}\text { f } \\
\text { m } \\
\text { m } \\
\text { f } \\
\text { f } \\
\text { f } \\
\text { f } \\
\text { f } \\
\text { f }\end{array}$ & $\begin{array}{l}\text { DAT } \\
\text { CVD } \\
\text { CVD } \\
\text { DAT } \\
\text { DAT/Vascular } \\
\text { Prog. Dysphasia } \\
\text { Prog. Dyspraxia } \\
\text { DAT } \\
\text { DAT } \\
\text { Prog. Dyspraxia }\end{array}$ & $\begin{array}{r}6 \\
5 \\
0 \\
2 \\
10 \\
1 \\
15 \\
6 \\
4 \\
6\end{array}$ & $\begin{array}{l}0 \\
0 \\
0 \\
0 \\
1 \\
0 \\
3 \\
3 \\
1 \\
0\end{array}$ & $\begin{array}{l}0 \\
0 \\
0 \\
0 \\
1 \\
2 \\
2 \\
0 \\
0 \\
0\end{array}$ & $\begin{array}{r}5 \\
6 \\
12 \\
5 \\
8 \\
5 \\
18 \\
4 \\
3 \\
15\end{array}$ & $\begin{array}{r}3 \\
0 \\
15 \\
0 \\
0 \\
0 \\
3 \\
3 \\
0 \\
12\end{array}$ & $\begin{array}{l}\text { positive } \\
\text { positive } \\
\text { negative } \\
\text { positive } \\
\text { negative } \\
\text { negative } \\
\text { negative } \\
\text { negative } \\
\text { negative } \\
\text { negative }\end{array}$ & $\begin{array}{l}\text { increased } \\
\text { no change } \\
\text { decreased } \\
\text { increased } \\
\text { no change } \\
\text { no change } \\
\text { no change } \\
\text { no change } \\
\text { increased } \\
\text { increased }\end{array}$ \\
\hline
\end{tabular}

CVD: cerebrovascular disease. DAT: dementia of Alzheimer type.

terior temporo-parietal and focal deficits on a ${ }^{15} \mathrm{O}$ steady state positron emission tomography scan. Patient 2 had cerebrovascular disease with a pseudobulbar palsy, in the absence of upper motor neuron signs in the limbs. Patient 3 had a history of hypertension and vascular disease, a left hemisensory disturbance, and memory impairment, with no pyramidal signs. Patients 7 and 10 had a progressive dyspraxia thought to be degenerative, although the cause has not yet been established. Patient 6 had a progressive expressive dysphasia, with good comprehension (understood three stage commands), also thought to be degenerative. CT on most patients showed mild to moderate generalised cortical atrophy, but in patient 6 the atrophy was predominantly on the left. Patient 2 had extensive white matter change attributed to ischaemia.

The responses were scored as follows: on the apraxia score, 2 points were given for no response, and one point for an inappropriate response. The maximum scores were 18 in the upper limb, 6 in the lower limb and 6 for orofacial apraxia. Gegenhalten was assessed at each joint, as described above, and scored from 0 (no rigidity) to 3 (severe rigidity). Maximum scores were 18 in the upper limb and 15 in the lower limb.

\section{Results (table)}

After the instruction to relax, gegenhalten became more pronounced in four of the 10 patients, but in only one patient (patient 3) was there any improvement.

Clenching the contralateral fist, (or clenching the teeth in one patient who was severely dyspractic), and counting backwards from 10, did not lead to any increase in the degree of rigidity in any of the patients. In nine of the 10 patients, apraxia of the upper limb was always associated with upper limb gegenhalten. There was no significant association between gegenhalten of the lower limbs and dyspraxia of the lower limbs (two of five patients). The limb placement sign was positive in only three patients.

Patient 3 was the only subject in whom no association between upper limb gegenhalten and upper limb dyspraxia was found. He was initially thought to have gegenhalten, but the fact that the instruction to relax improved the rigidity might suggest that in this patient the increase in tone may have been due to some other type of rigidity.

\section{Discussion}

Muscular rigidity is a common finding in elderly people, sometimes associated with bradykinesia, and a flexion attitude of limbs, trunk and neck. Rigidity has been described in association with a variety of disorders, including dementia and arteriosclerotic disease. Nosological confusion has arisen from the number of terms used to describe it; "paratonia", 2 "gegenhalten, ${ }^{1}$ and arteriosclerotic rigidity. 6 More recently, an extrapyramidal rigidity, likened to that of Parkinson's disease, has been described in a group of patients with Alzheimer's disease. ${ }^{7}$

Dupre described paratonic rigidity as an inability to relax a group of muscles, occurring together with brisk reflexes and an extensor plantar response, constituting the "débilite motrice" that he associated with a "débilite mentale". Gegenhalten, or "counterpull", was defined by Kleist as "a pure motor negativism, resisting changes of position, such that any attempt to change the position of a limb, or a part of the body, by passive movement, is met by a muscular tension which increases as the examiner changes his force, that is an active resistance to changes of position." Negativism had previously been thought to be an abnormality of "will", as part of a general negativism in a psychic disturbance (Kahlbaum quoted by Kleist), whilst Kraeplin (quoted by Kleist) described it as part of an "inner drive" on the part of the patient to be obstructive. Kleist disagreed with this view, noting that gegenhalten is usually a focal phenomenon, affecting certain limbs or muscle groups, particularly the adductors of both upper and lower limbs. He observed that this rigidity could be elicited by repeated movements from muscles where it was initially not obvious, and could occur spontaneously, 
thus causing abnormalities of posture whilst at rest. Kleist's observations were on a group of patients with a variety of neurological disorders, including catatonia and arteriosclerotic disease.

The term "tonic innervation", 89 describes the inability to relax a given innervation in any muscle group. Although dyspraxia was often associated with this phenomenon, it was not essential to it. Tonic innervation was described as always being associated with pyramidal signs, although it was distinguished from spasticity, because it is at its most marked in association with mild weakness. However, this association with pyramidal signs also distinguishes it from gegenhalten.

Critchley ${ }^{6}$ described "arteriosclerotic rigidity" in elderly patients with cerebrovascular degeneration, made more pronounced by the patient's inability to relax once his limbs were under examination. This phenomenon is associated with pyramidal signs, which makes interpretation difficult. A number of other authors have described rigidity in neurodegenerative disease, calling it akinetic rigidity, ${ }^{10}$ and hypertonia of opposition. ${ }^{11}$ Like Kleist's gegenhalten, it is associated with a general attitude of flexion, particularly of the neck muscles (the "psychological pillow"), ${ }^{10}$ and with a positive limb placement sign. The rigidity that was observed in the present series of patients is identical to that described by Kleist; although the terms paratonia and gegenhalten are often used interchangeably, Dupre's definition of paratonia included an association with brisk reflexes and extensor plantar responses. The rigidity associated with Alzheimer's disease has recently been likened to the extrapyramidal rigidity of Parkinson's disease, with parallels being drawn between the two disorders. $^{71213}$ It is likely, however, that in at least some cases the rigidity described may be gegenhalten. The absence of exacerbation of the rigidity during contralateral reinforcement may provide a distinction from extrapyramidal rigidity. The limb placement sign was only positive in three patients and does not appear to be useful as a criterion for diagnosis of gegenhalten. The increase in tone failed to improve after the instruction to relax in all our patients, apart from patient 3 , but this does not distinguish it from extrapyramidal rigidity.

The observed association between upper limb gegenhalten and dyspraxia may only reflect a shared anatomical substrate both being observed in patients with frontal lobe disorders. Alternatively, the perceived resistance to movement may reflect the inappropriate execution of movements as a feature of dyspraxia. The instruction to relax has been noted to exacerbate gegenhalten by a number of observers, ${ }^{2} 14$ and this is confirmed in our study. This phenomenon was striking in one patient in whom an abnormality of tone was minimal unless the instruction to relax was given. This abnormality on instruction can be compared to the dyspraxia occurring with verbal command, and as such gegenhalten could be viewed as a feature of ideomotor dyspraxia. However, we have not been able to assess on the available data whether gegenhalten is associated with a specific type of dyspraxia and in particular whether it is commoner with dyspraxia associated with frontal as opposed to parietal damage.

We thank the following for permission to study their patients: Dr D Thomas, St Mary's Hospital, London, Dr D Cronin, Warley Hospital, Brentwood, Prof Brice Pitt, St Charles' Hospital, London.

\section{References}

1 Kleist K. Gegenhalten (Motorischer Negativismus) Zwangsgreifen und Thalamus Opticus. Monatschr Psychiat Neurol 1927;65:317.

2 Dupre E. Debilite mentale et debilite motrice associe. Abstr Rev Neurologique 1910;XX:54.

3 Jenkyn LR, Walsh DB, Culver CM, Reeves AG. Clinical signs in diffuse cerebral dysfunction. $J$ Neurol Neurosurg Psychiatry 1977;40:956-66.

4 Tweedy J, Reding M, Garcia C, et al. Significance of cortical disinhibition signs. Neurology 1982;32:169-73.

5 De Renzi E, Motti F, Nichelli P. Imitating gestures: a quantitative approach to Ideomotor Apraxia. Arch Neurol 1980;37:6-10.

6 Critchley M. The neurology of old age. Lancet 1931; i: $1221-30$.

7 Pearce J. The extrapyramidal disorder of Alzheimer's Disease. Eur Neurol 1974;12:94-103.

8 Wilson SAK, Walsh FMR. The phenomenon of tonic innervation and its relation to motor apraxia. Brain 1914;37:199-246.

9 Walsh FMR, Robertson EG. Observations upon the form and nature of the "grasping" movements and "tonic innervation" seen in certain cases of lesion of the frontal lobe. Brain 1933;56:40-70.

10 Steck H. Les syndromes extrapyramidaux dans les maladies mentales. Schweiz Arch Neurol Psychiat 1926; 19:195.

11 De Ajuriaguerra J, Rego A, Tissot R. Activités motrices stereotypees dans les demences du grand âge. Ann Med Psycholo (Paris) 1963;5:641-64.

12 Molsa PK, Marttila RJ, Rinne VK. Extrapyramidal signs in Alzheimer's Disease. Neurology 1984;35: 453-61.

13 Leverenz J, Sumi SM. Parkinson's disease in patients with Alzheimer's disease. Arch Neurol 1986;43:662-4.

14 Paulson G, Gottlieb G. Developmental reflexes: The reappearance of foetal and neonatal reflexes in aged patients. Brain 1968;91:37-52. 